\title{
Effects of Film Stress and Geometry on Texture Evolution Before and After the Martensitic Transformation in a Nanocrystalline Co Thin Film
}

\author{
SUNG BO LEE, DONG-IK KIM, YANGHOO KIM, SEUNG JO YOO, JI YOUNG BYUN, \\ HEUNG NAM HAN, and DONG NYUNG LEE
}

\begin{abstract}
Using a transmission electron microscopy-based orientation and phase mapping technique we examine effects of film stress and geometry on texture development before and after the martensitic transformation in a nanocrystalline Co thin film. Specimens are annealed for various times at $873 \mathrm{~K}\left(600{ }^{\circ} \mathrm{C}\right)$, which is above the equilibrium martensitic transformation temperature $\left[\sim 693 \mathrm{~K}\left(\sim 420{ }^{\circ} \mathrm{C}\right)\right]$, and then cooled to room temperature. The cooled specimens are used for texture analysis. The martensitic transformation is observed to be incomplete, and fcc and hcp structures coexist in all the specimens examined. It is deduced from the crystallographic orientation relationship of the martensitic transformation of Co that, during prolonged annealing at $873 \mathrm{~K}\left(600{ }^{\circ} \mathrm{C}\right)$, the major texture in the fcc phase is $\{101\}$, followed by $\{111\}$. In the cooled structure, the major texture component in the hop phase is $(0001)$, followed by $\{2 \overline{11} 0\}$. The $\{101\}$ texture is clarified by assuming that the film system is perfect elastic-plastic with the help of the concept of the Taylor factor. We conclude that the (0001) texture is produced by the surface energy minimization, which, however, does not elucidate the development of the $\{2 \overline{11} 0\}$ texture. The formation of the texture component is understood by considering the strain energy provided by a constraint imposed by neighboring grains. As annealing time increases, the hop phase expands its area, dominating over the fcc phase after prolonged annealing, which is also clarified by allowing for the geometrical constraint effect. The expansion of the hcp phase supports the possibility of surface nucleation of martensites.
\end{abstract}

DOI: $10.1007 / \mathrm{s} 11661-015-2778-7$

(C) The Minerals, Metals \& Materials Society and ASM International 2015

\section{INTRODUCTION}

CoBALT (Co) and Co-based alloys have been widely used as thin-film magnetic recording media. ${ }^{[1-7]}$ They undergo an allotropic transformation between two close-packed structures: hcp as a low-temperature phase and fcc as a high-temperature one. The transformation from the fcc structure to the hcp structure exhibits characteristics of a martensitic transformation. ${ }^{[6,8-11]}$ Martensite plates grow by the motion of Shockley partial dislocations (SPDs) along four equivalent types of $\{111\}$ planes, and the $(0001)$ planes are related to the $\{111\}$ planes of the fcc structure, revealing a specific crystallographic orientation relationship between fcc and hep Co..$^{[10-12]}$ For pure Co, it occurs at the equilibrium temperature of $\sim 693 \mathrm{~K}\left(\sim 420{ }^{\circ} \mathrm{C}\right)$ at ambi-

SUNG BO LEE, Research Professor, YANGHOO KIM, Research Scientist, HEUNG NAM HAN, Professor, and DONG NYUNG LEE, Emeritus Professor, are with the Department of Materials Science and Engineering and Research Institute of Advanced Materials, Seoul National University, Seoul 151-744, Republic of Korea. Contact e-mails: bolee@snu.ac.kr,hnhan@snu.ac.kr DONG-IK KIM and JI YOUNG BYUN, Principal Research Scientists, are with the Korea Institute of Science and Technology, Seoul 136-791, Republic of Korea. SEUNG JO YOO, Research Scientist, is with the Korea Basic Science Institute, Daejeon 305-806, Republic of Korea.

Manuscript submitted September 6, 2014.

Article published online February 10, 2015 ent pressure. ${ }^{[8-12]}$ Bauer et al. ${ }^{[11]}$ examined the kinetics of the martensitic transformation in a polycrystalline Co bulk material using differential scanning calorimetry, and suggested that the transformation is characteristic of athermal nucleation and thermally activated, interface controlled growth because the mobility of SPDs is limited by lattice resistance. The martensitic transformation into hcp is accompanied by a macroscopic distortion due to the change in atomic distances. The lattice expands by $0.021 \mathrm{pct}$ parallel to and shrinks by 0.242 pct normal to the close-packed plane, ${ }^{[13]}$ and as will be discussed later, the macroscopic distortion seems to play a crucial role in the development of a major texture component in the hcp phase. Out of the two phases, the hcp phase is favored in thin films for magnetic recording, because, for $\mathrm{Co}$, its magnetocrystalline anisotropy energy is about one order of magnitude larger than that of the fcc phase ${ }^{[14,15]}$ Therefore, a mixture of hcp and fcc phases causes poor magnetic properties for magnetic recording. The minimum grain size which can be used in the media is limited by a balance between high signal-to-noise ratios and a thermal effect called superparamagnetism, which require grains to be as small as possible and large enough, respectively. ${ }^{[6,7]}$ It is calculated to be several nanometers in diameter and is experimentally implemented..$^{[1,2,4-7]}$ Therefore, understanding of the martensitic transfor- 
mation in a nanocrystalline Co thin film as a model material would be crucial for phase control for the magnetic recording media.

Thin films usually develop in-plane stresses because of a lattice mismatch at the interface or by a difference in thermal expansion coefficient between the layers. Hence, for texture control in nanocrystalline $\mathrm{Co}$ and its alloy thin films, understanding of effects of film stress and geometry on texture evolution in such thin films is prerequisite. However, an in-depth knowledge of the effects has been missing. For Co and its alloys, the situation is further complicated by the allotriomorphic phase transformation between fcc and hep phases. Moreover, fine grain sizes in nanocrystalline films has made difficult the acquisition of comprehensive texture and phase information encompassing area fractions of texture components and phase fractions.

The present study deals with texture evolution in a nanocrystalline Co film with the initial grain diameter smaller than $10 \mathrm{~nm}$. We aim to illuminate effects of film stress and geometry on the annealing texture evolution of the fcc phase during annealing at a temperature of $873 \mathrm{~K}\left(600{ }^{\circ} \mathrm{C}\right)$ above the equilibrium martensitic transformation temperature, below which hep is stable, and to also monitor the texture evolution of the hcp phase transformed after cooling to room temperature. This material is expected to have little dislocation density due to its small grain size, and in this case, recrystallization driven by the reduction of dislocation density is unlikely to occur. Thus, this work concentrates on the grain growth texture evolution. If films contain a high density of dislocations, they could exhibit the recrystallization texture during annealing, which is outside the scope of the present study. Readers interested in the topic should refer to a review article by Lee. ${ }^{[16]}$

The aforementioned obstacle to texture measurement in a nanocrystalline material arising from its small grain size was overcome by using a novel automatic orientation and phase mapping technique for transmission electron microscopy (TEM). Texture of both hep and fcc phases were analyzed at room temperature after cooling from $873 \mathrm{~K}\left(600^{\circ} \mathrm{C}\right)$. For the quantitative texture analysis, the area fractions of low-index texture components of each phase were calculated, such as (0001), $\{10 \overline{1} 0\}$, and $\{2 \overline{11} 0\}$ for hcp, and $\{001\},\{112\}$, $\{101\}$, and $\{111\}$ for fcc. (Throughout the whole paper, the orientation is defined as indices of crystal planes parallel to the film surface. See Section II for more statements.) All the film specimens examined show a mixture of the two phases. It is deduced from the crystallographic orientation relationship between fcc and hep Co that, during prolonged annealing at $873 \mathrm{~K}$ $\left(600{ }^{\circ} \mathrm{C}\right)$, the major texture in the fcc phase is $\{101\}$, followed by $\{111\}$. In the cooled structure, the major texture component in the hcp phase is (0001), followed by $\{2 \overline{11} 0\}$. The $\{101\}$ texture is clarified by assuming that the Co film system is perfect elastic-plastic and also by relying on the concept of the Taylor factor (TF). The (0001) texture is produced by the surface energy minimization, but the surface energy minimization does not elucidate the development of the $\{2 \overline{11} 0\}$ texture. We suggest that the formation of the $\{2 \overline{110}\}$ component is explained in terms of a constraint geometrically imposed by neighboring grains. It is also interesting to note that, as annealing time at $873 \mathrm{~K}\left(600{ }^{\circ} \mathrm{C}\right)$ increases, the area fraction of the hep phase calculated after cooling to room temperature increases, eventually exceeding that of the fcc phase after prolonged annealing, which is also understood by considering the geometrical constraint. Taken together, our observations suggest that the texture evolution before and after the martensitic transformation in the nanocrystalline Co thin film is influenced by both the surface energy minimization and the minimization of two types of strain energies, i.e., the strain energy due to differential thermal expansion and that provided by the geometrical constrain imposed by neighboring grains.

\section{EXPERIMENTAL}

Cobalt films were deposited by RF magnetron sputtering at room temperature onto amorphous $\mathrm{SiN}_{x} / \mathrm{Si}$ TEM grids (SiMPore Inc., West Henrietta) with a single electron-transparent window of $25 \times 25 \mu \mathrm{m}^{2}$. The Co target purity was 99.9 pct. The thickness of the $\operatorname{SiN}_{x}$ membrane which was deposited on $100-\mu$ m-thick $\mathrm{Si}(001)$ was $5 \mathrm{~nm}$. During deposition, the base pressure in the main chamber and the working pressure were $3 \times 10^{-6}$ Torr and $2.5 \mathrm{mT}$ Torr, respectively. The Ar flow rate was $15 \mathrm{sccm}$. The RF power was $150 \mathrm{~W}$. The Co film thickness was determined to be $\sim 50 \mathrm{~nm}$. The prepared film specimens were subsequently annealed isothermally at $873 \mathrm{~K}\left(600^{\circ} \mathrm{C}\right)$ for 30 minutes, 4, and 6 hours in a high-voltage TEM (JEM-ARM1300S, JEOL) operated at $1.25 \mathrm{MeV}(0.12 \mathrm{~nm}$ point-to-point resolution), which is equipped with a side-entry heating stage. The base pressure in the specimen chamber of the ARM was $1.5-2 \times 10^{-8}$ Torr. The heating rate used was $20 \mathrm{~K} / \mathrm{min}$. The cooling was done by turning off a heating stage controller connected to the TEM specimen heating holder. The cooling rates from $873 \mathrm{~K}$ to $373 \mathrm{~K}$ $\left(600{ }^{\circ} \mathrm{C}\right.$ to $\left.100{ }^{\circ} \mathrm{C}\right)$ and from $373 \mathrm{~K}\left(100{ }^{\circ} \mathrm{C}\right)$ to room temperature were measured to be $\sim 264$ and $\sim 3.6 \mathrm{~K} / \mathrm{min}$, respectively.

The as-deposited specimen and those cooled after annealing at $873 \mathrm{~K}\left(600{ }^{\circ} \mathrm{C}\right)$ were examined for analyses of texture evolution and grain size distributions with post-deposition annealing by using an orientation and phase mapping technique (ASTAR) (NanoMEGAS, Brussels, Belgium) attached to a field-emission TEM (JEM 2100F) (JEOL, Japan). This novel technique produces orientation and phase maps similar to the electron backscatter diffraction (EBSD) map obtained in a scanning electron microscope, but exhibits a higher spatial resolution and reasonable acquisition speed for TEM based on nano-beam precession electron diffraction patterns. ${ }^{[17]}$ In the present study, the setup of the ASTAR system was adjusted to have a 2.4-nm spot size of the electron beam and 2.5 to 5-nm scanning step size. 
The raw data obtained from the system were processed using an Orientation Imaging Microscopy ${ }^{\top \mathrm{M}}$ $\left(\mathrm{OIM}^{\mathrm{TM}}\right) 6.2$ software (EDAX, Draper) to demonstrate textures of the Co films in the form of inverse pole figure (IPF) and area fraction. The film texture is defined by $\{h k l\} / /$ film surface for fcc phase and, for hcp phase, $\{h k i l\} / /$ film surface, which indicates that the $\{h k l\}$ or $\{h k i l\}$ plane of the deposit is parallel to the film surface. Henceforth, this notation will be briefly cited in the text as $\{h k l\}$ for fcc and $\{h k i l\}$ for hcp, respectively.

Orientation data were processed by grain unit. Grains were identified by a 5 deg-misorientation criterion and misorientations exceeding the tolerance value were interpreted as grain boundaries. Grains under two pixels were replaced by surrounding pixels to minimize the misindexing influence. For grain size analysis, grains meeting at twin boundaries were considered as one grain. The strength of a texture component $(f(g)$ value) in orientation distribution function (ODF) space cannot reflect the volume fraction of the component directly because there exist overlapped equivalent points of the component in ODF space, which results in the concept of multiplicity. ${ }^{[18]}$ The higher the number of overlapped equivalent points of a texture component in ODF space, the larger its $f(g)$ value. Therefore, in the present study, for the quantitative texture analysis, we directly calculated area fractions of each texture component $(\{001\},\{112\},\{101\}$, and $\{111\}$ for fcc and (0001), $\{2 \overline{110}\}$, and $\{10 \overline{10}\}$ for hep) from ASTAR orientation data. The 10 deg-misorientation criterion is introduced for the determination of each data point as the major texture components, because over this criterion, areas for the $\{112\}$ and $\{111\}$ components are overlapped.

\section{RESULTS}

Figure 1 shows the orientation mapping images (left panel) and corresponding IPFs (right panel) of the hcp and fcc phases in the as-deposited specimens and those annealed at $873 \mathrm{~K}\left(600{ }^{\circ} \mathrm{C}\right)$ for 30 minutes, 4, and 6 hours. While the fcc phase in the as-deposited specimen is highly $\{101\}$-textured (Figure 1(a)) with the $\{001\}$ component exhibiting a similar texture strength, for the hcp phase the (0001) component shows the highest texture strength. Such tendencies of the fcc and hcp phases remain largely unchanged in the annealed specimens (Figures 1(c) through (h)).

To trace the texture evolution with increasing annealing time more quantitatively, we rely on the calculation of area fraction (Figure 2). In Figure 2, the area fraction of representative texture components of the two phases are plotted as a function of annealing time. Note that all the fraction values used are total fractions. The total fraction of a texture component means an area fraction of the component with reference to the whole area encompassing both phases. For the fcc phase, as annealing time increases, the total fractions of the $\{001\},\{112\}$, and $\{101\}$ components are largely decreasing, while that of the $\{111\}$ component remains unchanged (Figure 2(a)), which indicates a decrease of the area fraction of the fcc phase with increasing annealing time. For the hcp phase, as annealing time increases, the total fractions of the (0001) and $\{2 \overline{11} 0\}$ components increases with that of the $\{10 \overline{1} 0\}$ component gradually decreasing (Figure 2(b)). In the as-deposited specimen, the $\{10 \overline{1} 0\}$ component occupies the largest area fraction out of the hep components, followed by the (0001) component. However, in the annealed specimens, the $\{10 \overline{1} 0\}$ component becomes minor with annealing and the major texture component turns to (0001). Interestingly, as annealing time increases at $873 \mathrm{~K}\left(600^{\circ} \mathrm{C}\right)$, the hcp phase expands its area, being dominant over the fcc phase after the prolonged annealing (i.e., 4 and 6 hours) (Figure 2(c)). All the fraction values used for Figure 2 are summarized in Table I.

As noted before, all the area fractions, including those of the fcc texture components, are calculated from the cooled specimens, but not during annealing at $873 \mathrm{~K}$ $\left(600{ }^{\circ} \mathrm{C}\right)$, where only the fcc phase is stable. Using the observed values of the area fractions of the fcc components as well as those of the hcp texture components, though approximately, we could estimate the area fraction of the fcc components during annealing. We designate the real area fraction of each fcc components at $873 \mathrm{~K}\left(600{ }^{\circ} \mathrm{C}\right)$ as $\boldsymbol{A}\{h k l\}$. After cooling from $873 \mathrm{~K}$ $\left(600{ }^{\circ} \mathrm{C}\right)$ to room temperature, the $\{h k l\}$ component is partly transformed into hcp, revealing the crystallographic orientation relationship between fcc and hcp Co $\left[(111)_{\mathrm{fcc}} / /(0001)_{\mathrm{hcp}}\right.$ and $\left.[10 \overline{1}]_{\mathrm{fcc}} / /[11 \overline{2} 0]_{\mathrm{hcp}}\right]$. The transformed fraction of the $\{h k l\}$ component is termed as $\boldsymbol{X}\{h k l\} . \boldsymbol{A}\{h k l\}$ is simply expressed as

$$
\boldsymbol{A}\{h k l\}=(1-\boldsymbol{X}\{h k l\}) \cdot \boldsymbol{A}\{h k l\}+\boldsymbol{X}\{h k l\} \cdot \boldsymbol{A}\{h k l\},
$$

where $(1-\boldsymbol{X}\{h k l\}) \cdot \boldsymbol{A}\{h k l\}$ is equivalent to the fraction value obtained from the cooled specimen, which is termed as $\boldsymbol{O}\{h k l\} . \boldsymbol{X}\{h k l\} \cdot \boldsymbol{A}\{h k l\}$ is equal to the area fraction of the hcp components transformed from $\{h k l\}$ after cooling. Hence,

$$
\boldsymbol{A}\{h k l\}=\boldsymbol{O}\{h k l\}+\boldsymbol{A}\{h k l-\operatorname{tr}\},
$$

where $h k l$-tr means the hcp orientations transformed from $\{h k l\}$. From the aforementioned orientation relationship, simply,

$$
\begin{aligned}
& \boldsymbol{A}\{111-\operatorname{tr}\}=\boldsymbol{A}\{0001\}, \boldsymbol{A}\{101-\operatorname{tr}\}=\boldsymbol{A}\{2 \overline{11} 0\}, \\
& \quad \text { and } \boldsymbol{A}\{112-\operatorname{tr}\}=\boldsymbol{A}\{10 \overline{1} 0\} .
\end{aligned}
$$

(All the $\boldsymbol{O}\{h k l\}$ and $\boldsymbol{A}\{h k i l\}$ for low-index texture components are used in Figures 2(a) and (b) and listed in Table I.)

First we consider the specimen annealed at $873 \mathrm{~K}$ $\left(600{ }^{\circ} \mathrm{C}\right)$ for 30 minutes. Minor orientations revealing weak texture strengths shown in the IPF are excluded from the consideration, because their area fractions are found to be not so large as compared with those of the fcc and hep major texture components. This exclusion applies to the other specimens. From Table I, 


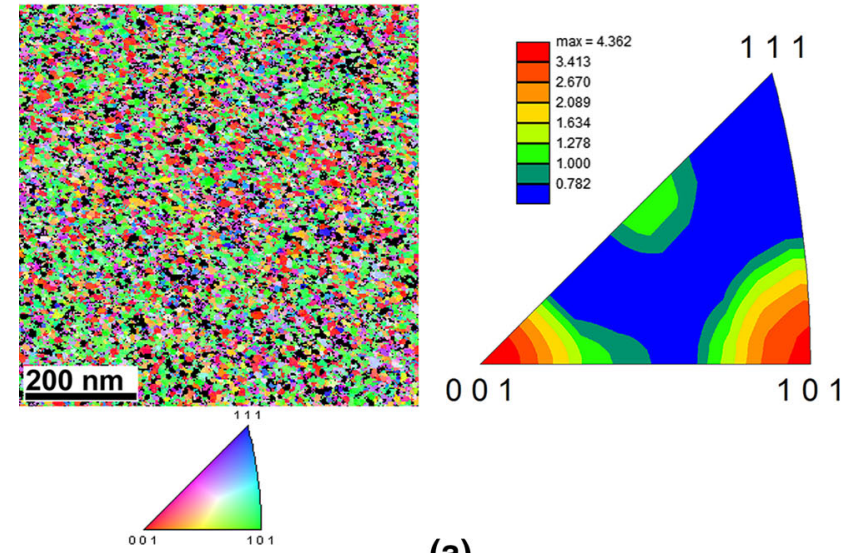

(a)
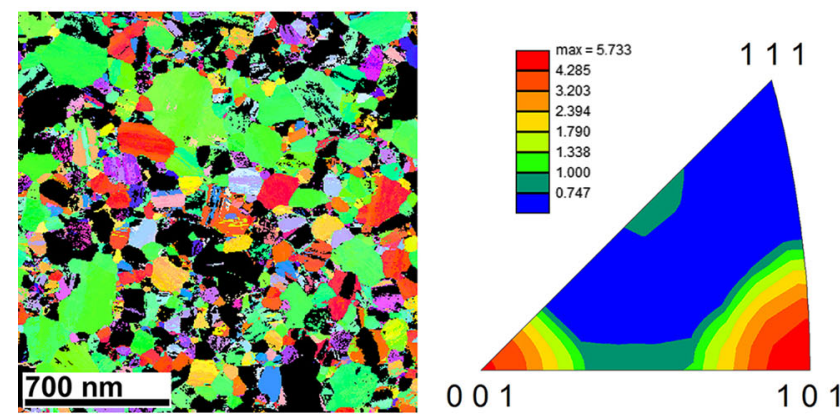

(c)
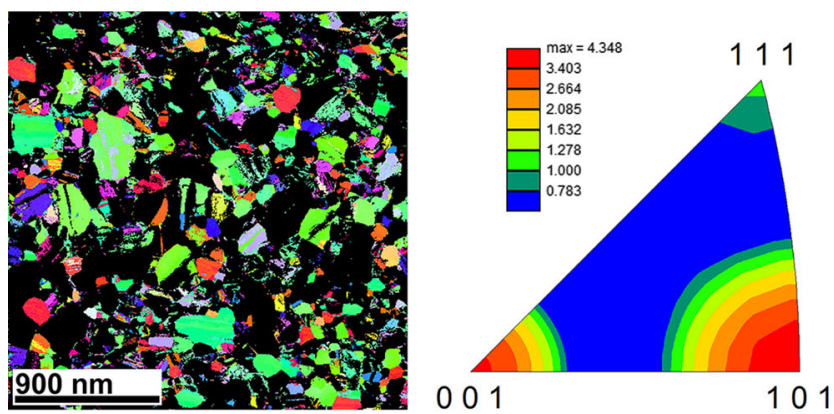

(e)
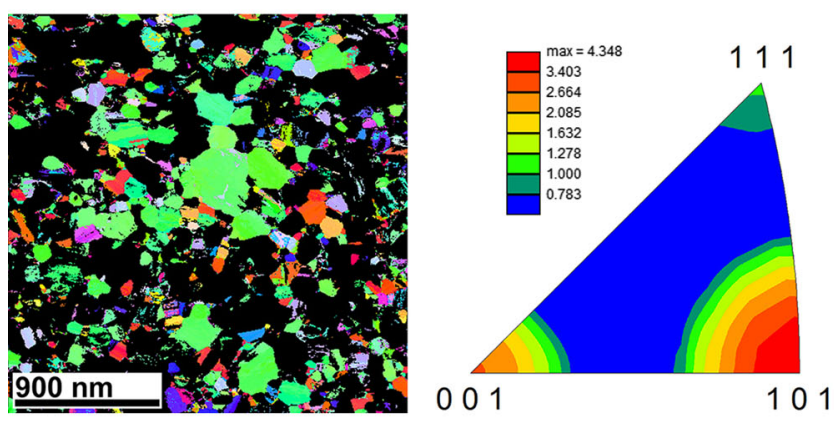

(g)
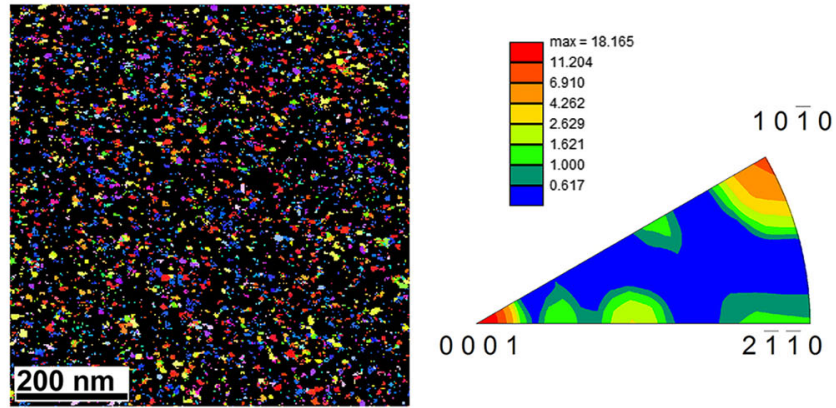

(b)
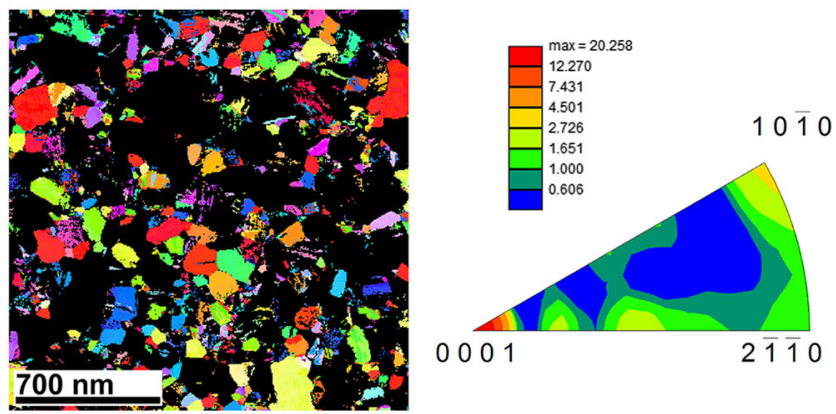

(d)
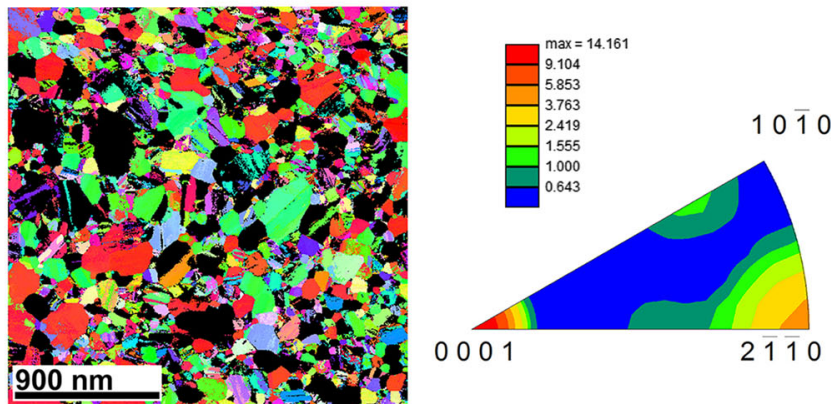

(f)
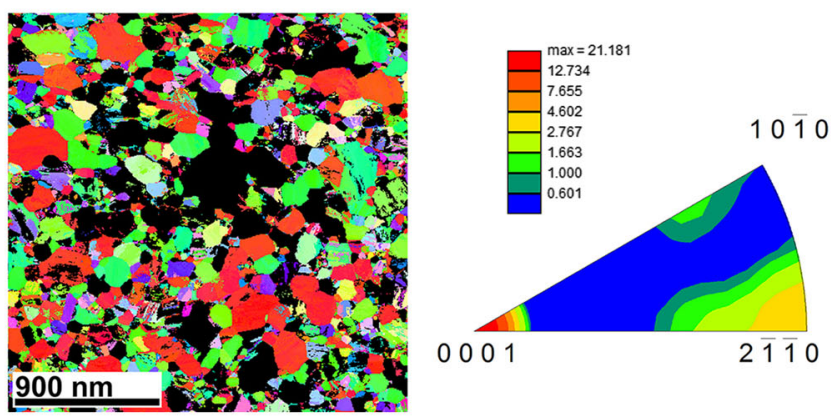

(h)

Fig. 1-Orientation mapping image (left panel), color-coded by crystallographic orientations, and a corresponding IPF (right panel) of (a) the fcc phase and $(b)$ the hcp phase in the as-deposited film. $(c)$ and $(d)$ are obtained from the specimen cooled after annealing at $873 \mathrm{~K}\left(600{ }^{\circ} \mathrm{C}\right)$ for 30 min. $(e)$ and $(f)$ are from the specimen cooled after annealing for $4 \mathrm{~h} .(g)$ and $(h)$ are from the specimen cooled after annealing for $6 \mathrm{~h}$. (c), (e) and (g) apply to the fcc phase with (d), (f), and (h) corresponding to the hcp phase. The color bar beside the IPF indicates texture strength (Color figure online). 


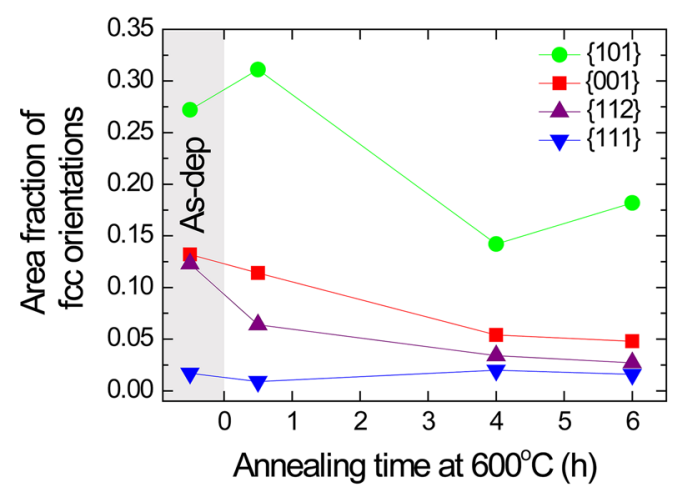

(a)

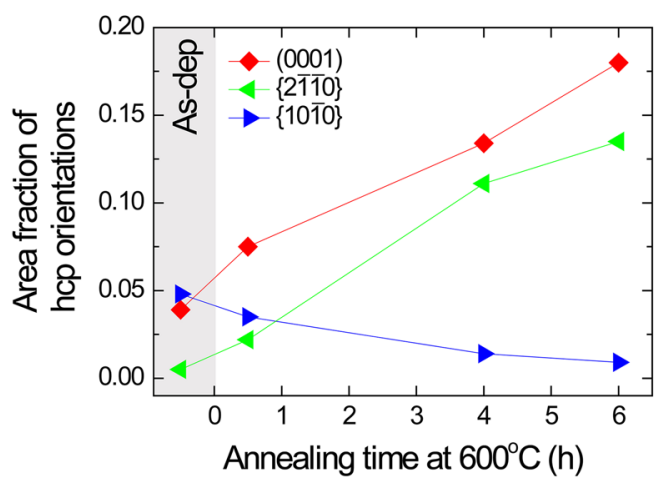

(b)

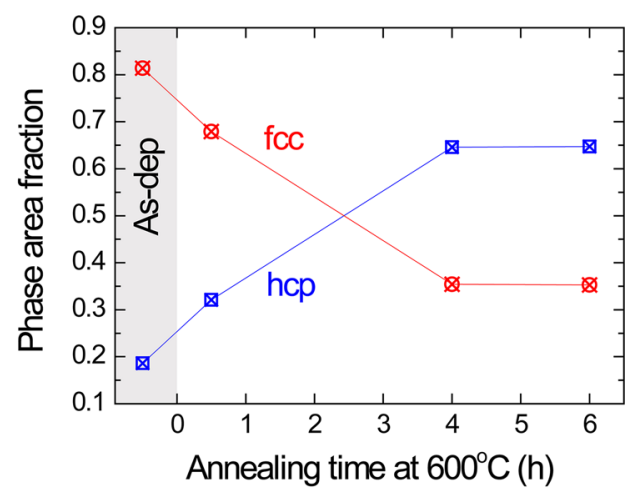

(c)

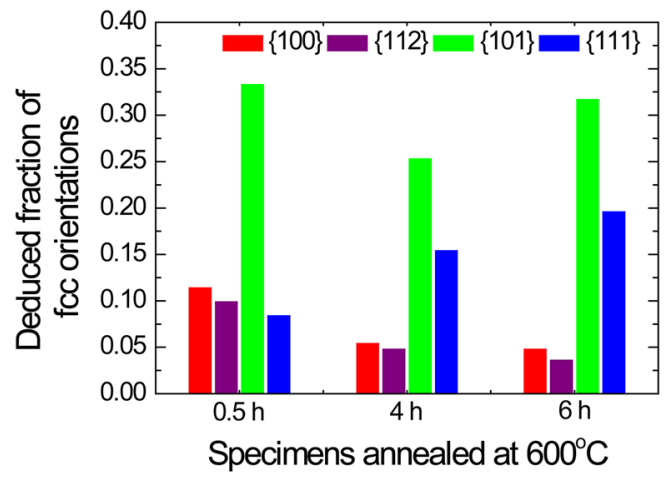

(d)

Fig. 2-Variation of the area fractions of representative texture components with increasing annealing time at $873 \mathrm{~K}\left(600{ }^{\circ} \mathrm{C}\right)$ for $(a)$ the fcc phase and $(b)$ the hcp phase. $(c)$ the time evolution of the area fraction of each phase. (d) Deduction of the area fractions of fcc orientations during annealing at $873 \mathrm{~K}\left(600^{\circ} \mathrm{C}\right)$ for $30 \mathrm{~min}, 4$, and $6 \mathrm{~h}$. (See text for details.) Note that all fraction values used are total fractions (Color figure online).

Table I. Summary of the Area Fractions of Low-Index fcc and hep Texture Components in the As-Deposited Specimen (As-Dep) and the Specimens Annealed at $873 \mathrm{~K}\left(600{ }^{\circ} \mathrm{C}\right)$ for $30 \mathrm{~min}(600-0.5)$, for $4 \mathrm{~h}(600-4)$, and for $6 \mathrm{~h}(600-6)$

\begin{tabular}{|c|c|c|c|c|c|c|c|c|c|}
\hline & $\{001\}$ & $\{112\}$ & $\{101\}$ & $\{111\}$ & (0001) & $\{2 \overline{11} 0\}$ & $\{10 \overline{1} 0\}$ & fcc & hcp \\
\hline As-Dep & 0.132 & 0.123 & 0.272 & 0.017 & 0.039 & 0.005 & 0.048 & 0.814 & 0.186 \\
\hline $600-0.5$ & 0.114 & 0.064 & 0.311 & 0.009 & 0.075 & 0.022 & 0.035 & 0.679 & 0.321 \\
\hline $600-4$ & 0.054 & 0.034 & 0.142 & 0.02 & 0.134 & 0.111 & 0.014 & 0.354 & 0.646 \\
\hline $600-6$ & 0.048 & 0.027 & 0.182 & 0.016 & 0.18 & 0.135 & 0.009 & 0.353 & 0.647 \\
\hline
\end{tabular}

The last two columns present the area fractions of the two phases.

$\boldsymbol{A}\{0001\}=0.075, \boldsymbol{A}\{2 \overline{11} 0\}=0.022$, and $\boldsymbol{A}\{10 \overline{1} 0\}=0.035$.

And,

$$
\begin{aligned}
& \boldsymbol{O}\{001\}=0.114, \boldsymbol{O}\{112\}=0.064, \boldsymbol{O}\{101\}=0.311, \\
& \boldsymbol{O}\{111\}=0.009 .
\end{aligned}
$$

From the above formulations,

$$
\begin{aligned}
& \boldsymbol{A}\{001\}=\boldsymbol{O}\{001\}+\boldsymbol{A}\{001-\operatorname{tr}\}=0.114, \\
& \boldsymbol{A}\{112\}=\boldsymbol{O}\{112\}+\boldsymbol{A}\{112-\operatorname{tr}\}=0.099, \\
& \boldsymbol{A}\{101\}=\boldsymbol{O}\{101\}+\boldsymbol{A}\{101-\operatorname{tr}\}=0.333, \\
& \boldsymbol{A}\{111\}=\boldsymbol{O}\{111\}+\boldsymbol{A}\{111-\operatorname{tr}\}=0.084 .
\end{aligned}
$$

Likewise, for the specimen annealed for 4 hours,

$$
\begin{aligned}
& \boldsymbol{A}\{001\}=0.054, \boldsymbol{A}\{112\}=0.048, \boldsymbol{A}\{101\}=0.253, \\
& \quad \text { and } \boldsymbol{A}\{111\}=0.154 .
\end{aligned}
$$

For the specimen annealed for 6 hours,

$$
\begin{aligned}
& \boldsymbol{A}\{001\}=0.048, \boldsymbol{A}\{112\}=0.036, \boldsymbol{A}\{101\}=0.317 \\
& \quad \text { and } \boldsymbol{A}\{111\}=0.196
\end{aligned}
$$

The deduced fractions of the fcc orientations are plotted in Figure 2(d). The $\{101\}$ component is always a major texture component in the fcc phase, regardless of annealing time, which is consistent with the IPF data (Figure 1). The above simple deduction shows the $\{111\}$ component, whose area fraction appears to be small in Figure 2(a), as making up a significant fraction and thus following the $\{101\}$ component. 


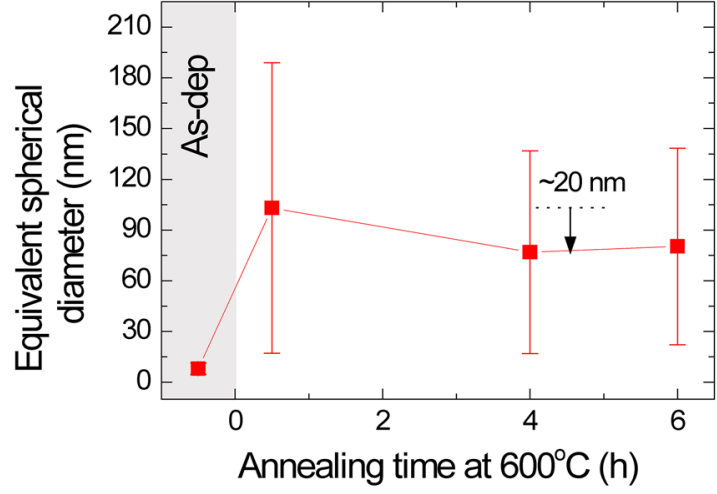

(a)

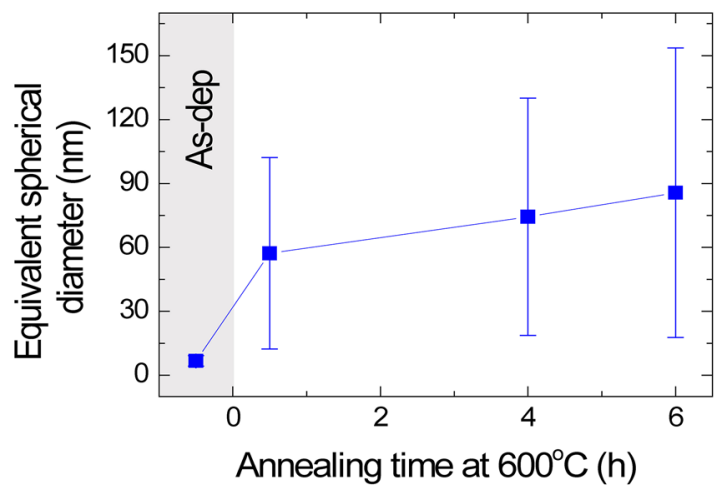

(b)

Fig. 3 - Grain size variation in (a) the fcc phase and (b) the hcp phase with increasing annealing time (Color figure online).

Figure 3 shows the grain size variation in the fcc and hcp phases with increasing annealing time. The mean grain diameter and standard deviation values specified in Figure 3 are not based on the number fraction per grain diameter, but on the area fraction. Generally, the calculation by considering the number fraction tends to underestimate increase in grain size due to grain growth. This is the reason why we used the area fraction per grain diameter for grain size analysis. The error bars shown in Figure 3 represent the standard deviations. Singularly, as annealing time increases, at variance with the hcp phase, which undergoes grain growth (Figure 3(b)), the fcc phase exhibits a decrease in mean diameter, e.g., by $\sim 20 \mathrm{~nm}$ from the annealing time of 30 minutes to 4 to 6 hours (Figure 3(a)). (Note that the mean grain sizes plotted in Figure 3 is not obtained in situ during annealing, but from the cooled structures.)

\section{DISCUSSION}

Although the deposition was done at room temperature, for the as-deposited specimen, the low-temperature phase (hcp), which is stable below $\sim 693 \mathrm{~K}$ $\left(\sim 420{ }^{\circ} \mathrm{C}\right)$, is dominated by the high-temperature phase (fcc), which occupies more than 80 pct of the area examined, as demonstrated in Figure 2(c) and Table I.
Because during sputtering the substrate is likely heated by the latent heat of deposition of Co during deposition, its temperature (nominally, room temperature, here) may be really well within the range of the fcc $\leftrightarrow$ hcp phase transformation temperatures, though not intentionally heated. We relate the higher fraction of the fcc phase in the deposition structure to the nanometer-scale grain size shown in Figure 3. For the small grain sizes of the as-deposited film ( $<10 \mathrm{~nm}$ ) (Figures 3(a) and (b)), the nucleation of SPDs responsible for the martensitic transformation is likely to be highly impeded, because applied stress is required to be very high for the activation of dislocation sources under this condition, ${ }^{[19]}$ which lets the transformation incomplete and thus reveals the dominant fraction of the fcc phase, as shown in Figure 2(c).

As can be seen in Figure 2(c), the annealed specimens reveal an incomplete martensitic transformation into hcp after cooling. The fraction of the hcp phase increases with increasing annealing time and, after 4 hours, is saturated to be $\sim 65$ pct. (We will address the increase in hcp fraction with increasing annealing time below soon.) The incomplete transformation is consistent with the model based on athermal nucleation and thermally activated growth proposed by Bauer et al., ${ }^{[11]}$ because the motion of SPDs would be retarded during cooling.

As shown in Figure 2(d), it is deduced that, after prolonged annealing (i.e., 4 and 6 hours), the major texture of the fcc phase is $\{101\}$, which is followed by $\{111\}$. Since the surface energy increases in order of $\{111\},\{100\},\{112\}$, and $\{101\}$ for fcc metals, ${ }^{[20]}$ the $\{101\}$ texture is not explained by the surface energy minimization. Then we have explored the possibility of explaining it in terms of the strain energy minimization, because film stress arises from the difference in thermal expansion coefficient between the film and the substrate. In our case, when heated to $873 \mathrm{~K}\left(600^{\circ} \mathrm{C}\right)$, the $\mathrm{Co} /$ $\mathrm{SiN}_{x}$ layer is likely to be subjected to a thermal strain, which arises from the difference in thermal expansion coefficient between the $\mathrm{Co} / \mathrm{SiN}_{x}$ layer and the $\mathrm{Si}(001)$ substrate. In this case, the $\mathrm{Co} / \mathrm{SiN}_{x}$ layer should be in a plane stress, equibiaxial strain state, ${ }^{[16,21,22]}$ because the 50-nm-thick $\mathrm{Co} / 5$-nm-thick $\mathrm{SiN}_{x}$ layer is much thinner than the Si substrate (100 $\mu \mathrm{m}$ thick), and thus its strain is controlled by the Si substrate, whose thermal expansion coefficient is isotropic.

The thermal strain, $\varepsilon$, due to differential thermal expansion is calculated by

$$
\varepsilon=\left(\alpha_{\mathrm{Co}}-\alpha_{\mathrm{Si}}\right) \cdot\left(T-T_{0}\right),
$$

where $\alpha$ and $T$ are thermal expansion coefficient and temperature, respectively, and the subscript, 0 , means the initial state. The thermal expansion coefficient of hcp Co $\left(\alpha_{\mathrm{Co}}^{\mathrm{hcp}}\right)$ is adapted from Reference 23 , and that of $\operatorname{Si}(001)\left(\alpha_{\mathrm{Si}}\right)$ from Reference 24 . The mean values between room temperature $\left[298 \mathrm{~K}\left(25^{\circ} \mathrm{C}\right)\right]$ and $693 \mathrm{~K}$ $\left(420^{\circ} \mathrm{C}\right)$ (the equilibrium transformation temperature) are used for the estimation of $\varepsilon$. $\alpha_{\mathrm{Co}}^{\text {hcp }}$ and $\alpha_{\mathrm{Si}}$ are $13.9 \times 10^{-6} \mathrm{~K}^{-1}$ and $3.5 \times 10^{-6} \mathrm{~K}^{-1}$, respectively. The hcp phase in the Co film receives compressive strain 


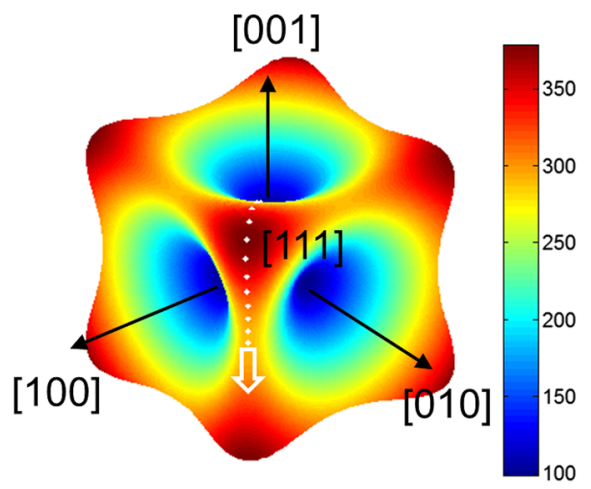

(a)

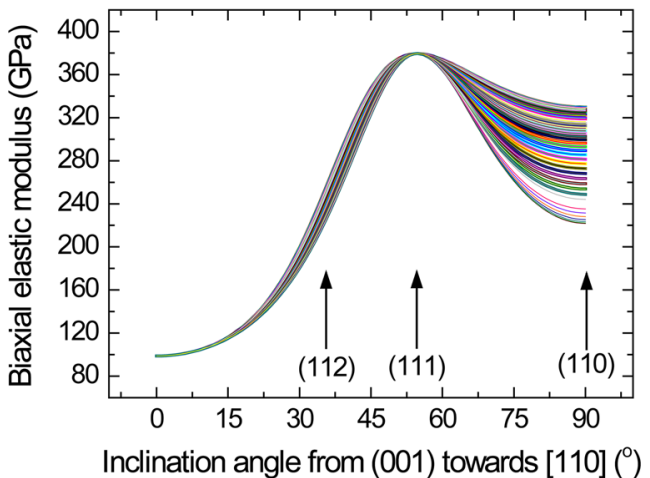

(b)

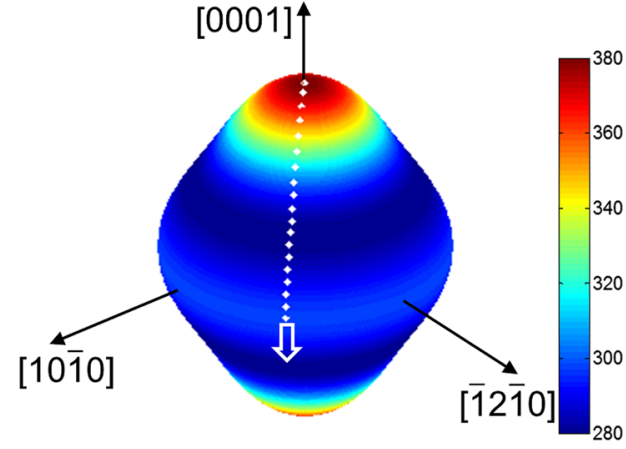

(c)

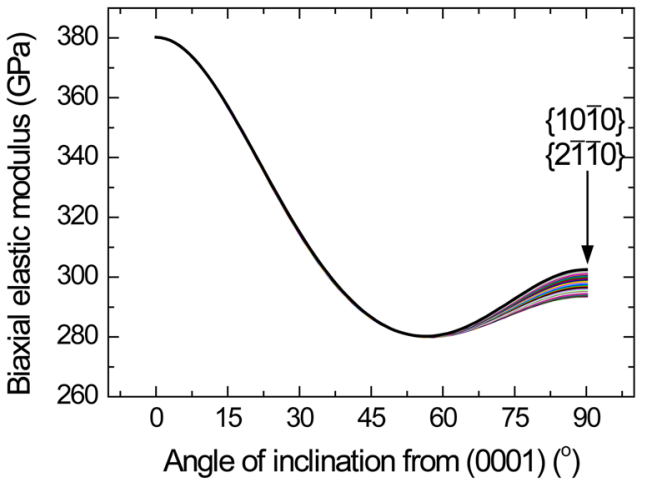

(d)

Fig. 4 - (a) The polar plot of the biaxial elastic modulus against the surface normal direction and $(b)$ a two-dimensional plot as a function of the angle of inclination from the (001) plane towards [110] for fcc Co. $(c)$ and $(d)$ are the polar plot and a two-dimensional plot as a function of the angle of inclination from the (0001) plane for hcp Co, respectively (Color figure online).

during cooling from $\sim 693 \mathrm{~K}\left(\sim 420^{\circ} \mathrm{C}\right)$ to room temperature. The thermal strain, $\varepsilon$, due to differential thermal expansion $\left[\left(\alpha_{\mathrm{Co}}^{\mathrm{hcp}}-\alpha_{\mathrm{Si}}\right) \cdot(693-298)\right]$ is calculated to be $\sim 4.1 \times 10^{-3}$. The thermal expansion coefficients of fcc $\operatorname{Co}\left(\alpha_{\mathrm{Co}}^{\mathrm{fcc}}\right)$ and $\operatorname{Si}(001)\left(\alpha_{\mathrm{Si}}\right)$ are determined by the same method as for hcp Co. The mean values between room temperature and $873 \mathrm{~K}\left(600{ }^{\circ} \mathrm{C}\right)$ are used for the estimation of the thermal strain. $\alpha_{\mathrm{Co}}^{\mathrm{fcc}}$ and $\alpha_{\mathrm{Si}}$ are $14.4 \times$ $10^{-6} \mathrm{~K}^{-1}$ and $3.7 \times 10^{-6} \mathrm{~K}^{-1}$, respectively. The fcc phase in the Co film will receive compressive strain during annealing, because the thermal expansion coefficient of fcc $\operatorname{Co}\left(\alpha_{\mathrm{Co}}^{\mathrm{fcc}}\right)$ is larger than that of $\mathrm{Si}(001)$. The thermal strain, $\varepsilon$, is calculated by $\varepsilon=\left(\alpha_{\mathrm{Co}}^{\mathrm{fcc}}-\alpha_{\mathrm{Si}}\right)$. $(873-298)$. It amounts to $\sim 6.1 \times 10^{-3}$.

The strain energy density (the strain energy per unit volume) $w$ of a film under the plane stress, equibiaxial strain $(\varepsilon)$ state is given by

$$
w=M_{\varepsilon} \cdot \varepsilon^{2},
$$

where $M_{\varepsilon}$ is the biaxial elastic modulus of the film under the plane stress, equibiaxial strain state. The biaxial elastic moduli of fcc planes under the equibiaxial strain, plane stress state are calculated using the elastic compliances of fcc Co. (See, for details, Appendix.) The biaxial elastic modulus varies with the surface normal direction and is thus represented as the polar plot against it
(Figure 4(a)). In Figure 4(a), the modulus values are indicated by not only distances from the origin, but also colors for high visibility. (See the code bar beside the plot.) It is calculated that the modulus values of only the $\{001\}$ and $\{111\}$ planes are independent of directions on those planes, i.e., univalued. The modulus values of other planes depend on directions on those planes, i.e., multivalued. The mean values are used in the polar plot. For simplicity's sake, the modulus is plotted as a function of the angle of inclination from the (001) plane towards [110] (indicated by a white dotted arrow in Figure 4(a)) (Figure 4(b)), from which we easily grasp the variation of the modulus with the surface normal direction. As demonstrated in the figure, the biaxial elastic modulus of the $\{001\}$ plane is minimum (98.7 $\mathrm{GPa})$ and that of the $\{111\}$ plane is maximum (379.5 GPa). Figure 4(b) clearly shows that the modulus values of only the $\{001\}$ and $\{111\}$ planes are univalued.

It follows from Figures 4(a) and (b) that the $\{101\}$ texture in the fcc phase cannot be simply explained by the elastic strain energy minimization, which favors $\{001\}$. However, as will be discussed below, we will get to know that the major $\{101\}$ component is understood by assuming that our film system is perfectly elasticplastic and introducing the concept of the TF.

As noted before, during annealing at $873 \mathrm{~K}\left(600^{\circ} \mathrm{C}\right)$, the fcc Co film deposit is calculated to undergo the 
equibiaxial compressive strain of $\sim 6.1 \times 10^{-3}$, and at such a high temperature, the critical resolved shear stress on active slip systems is expected to be lowered. Therefore, the deposit may undergo plastic deformation.

First, we consider that the magnitude of plastic strain is so large that every grain in the deposit undergoes the same equibiaxial plastic strain as the deposit itself does. This strain state is equivalent to an axisymmetric strain state. At a given plastic strain, operating slip systems and shear strains on the slip systems can differ depending on the orientation of each grain in the deposit. To accomplish an increment of plastic strain, $d \varepsilon_{i j}$ of a crystal specimen, the shear strains, $d \gamma^{(k)}$, are needed, where $d \gamma^{(k)}$ is the shear strain on the $k$ th slip system of the crystal. The ratio of the sum of shear strains on active slip systems to the plastic strain increment is often called the $\mathrm{TF},{ }^{[25]}$ which can be expressed as

$$
\mathrm{TF}=\Sigma d \gamma^{(k)} / d \varepsilon_{i j}
$$

The TF predicts that the strain energy of grains increases with increasing their TFs. Chin and Mammel $^{[26]}$ calculated orientation dependence of $\mathrm{TF}$ for axisymmetric deformation for $\{110\}\langle 111\rangle$ or $\{111\}\langle 110\rangle$ slip systems. Their calculation is applied to our case because the condition of axisymmetric deformation is equivalent to the equibiaxial strain state, as noted before. The TFs of $\{001\},\{112\},\{101\}$, and $\{111\}$ fcc crystals are $2.449,3.076,3.674$, and 3.674 , respectively. The TF of the $\{001\}$ crystal is the minimum and the $\{101\}$ and $\{111\}$ crystals have the maximum TF. This means that $\{001\}$ grains are expected to accumulate the minimum stored strain energy during plastic straining, while $\{101\}$ and $\{111\}$ grains accumulate the maximum stored energy with $\{112\}$ grains in between. Therefore, lower-TF grains seem likely to grow at the expense of neighboring grains with higher TFs.

At smaller strains, in contrast to the case of large strains, all grains in the Co deposit could not undergo the same strain as the deposit. Thus, some grains will undergo plastic deformation before others, and the plastically deformed grains are likely to have higher strain energy due to dislocations generated by plastic deformation than surrounding grains with different orientations, which still remain in the elastic regime. In fact, an increase in TF also means an increase in resistance to deformation and thus the above equation can be expressed as ${ }^{[27]}$

$$
\mathrm{TF}=\Sigma d \gamma^{(k)} / d \varepsilon_{i j}=\sigma_{i j} / \tau_{\mathrm{c}},
$$

where $\sigma_{i j}$ is the strength and $\tau_{\mathrm{c}}$ is the shear stress acting on all the active slip systems. For instance, grains which are oriented to have infinite TF cannot be plastically deformed. When a polycrystalline aggregate is subjected to a plastic deformation which is not so high enough to make the strengths of grains become similar, low TF grains are likely to deform before neighboring high TF grains. In this case, low TF grains have higher stored strain energy than high TF grains, which thereby makes high TF grains consume neighboring low TF grains. These phenomena have been found in annealing textures of $\mathrm{Ag},{ }^{[28,29]} \mathrm{Cu}$-bearing bake hardening steel, ${ }^{[30]} \mathrm{Al},{ }^{[31]}$ and a nanocrystalline $\mathrm{Cu} .{ }^{[32]}$

Taken together, at large strains, where all grains plastically deform, high TF grains are likely to have more stored energy than low TF grains, as noted in the previous paragraph. However, at small strains, low TF grains will deform more than high TF ones, because the former undergoes the elastic-to-plastic transition before the latter. For the sake of convenience, we consider $\{001\},\{112\},\{101\}$, and $\{111\}$ grains. $\{001\}$ grains are likely to begin to undergo plastic deformation before grains with other orientations because $\{001\}$ has the lowest TF.

For the thermal strain $\left(\sim 6.1 \times 10^{-3}\right)$ at $873 \mathrm{~K}$ $\left(600{ }^{\circ} \mathrm{C}\right)$ in the present study, we assume that our case belongs to the aforementioned, low-strain regime so that grains with orientations of lower TFs begin to undergo plastic deformation. The evolution of the strong $\{101\}$ texture after annealing at $873 \mathrm{~K}\left(600^{\circ} \mathrm{C}\right)$ can be explained by assuming that lower-TF grains, such as $\{001\}$ and $\{112\}$, have been plastically deformed at the high temperature, while $\{101\}$ and $\{111\}$ grains remain in the elastic regime: In this case, $\{101\}$ grains would grow at the expense of $\{111\}$ grains in the elastic regime because $\{101\}$ grains have a lower biaxial elastic modulus than $\{111\}$ grains. Simultaneously, they are likely to grow by consuming other oriented grains in the plastic regime, a growth which is driven by the stored strain energy of the plastically deformed grains. To sum up, it is presumed that $\{101\}$ grains are in the elastic regime with lower-TF grains, such as $\{001\}$ and $\{112\}$ grains, belonging to the plastic regime at the thermal strain at $873 \mathrm{~K}\left(600{ }^{\circ} \mathrm{C}\right)$. It follows that that $\{101\}$ grains are favored to grow by the elastic strain energy minimization, which explains the dominant $\{101\}$ texture in the fcc phase, as shown in Figure 2(d).

To explain the comparable fraction of $\{111\}$ deduced in the specimen annealed for prolonged annealings, we calculate and compare the driving force for grain growth by both strain energy minimization and surface energy minimization for $\{111\}$ and $\{101\} .\{111\}$ has the lowest surface energy for fcc Co and its value, $\gamma_{111}$, is calculated to be $2.70 \mathrm{~J} / \mathrm{m}^{2}$. ${ }^{[3]}$ The driving force by surface energy difference is given by

$$
P_{\text {surf }}=2 \cdot \Delta \gamma / d=2\left(\gamma_{101}-\gamma_{111}\right) / d,
$$

where $d$ is the film thickness of $50 \mathrm{~nm}$. According to Fruchart et al., ${ }^{[34]} \gamma_{101}$ is 1.06 times $\gamma_{111}$. Therefore, $P_{\text {surf }}=6.5 \mathrm{MPa}$.

The driving force by the strain energy minimization is expressed as

$$
P_{\text {strain }}=\left(M_{\varepsilon, 101}-M_{\varepsilon, 111}\right) \cdot \varepsilon^{2}
$$

$M_{\varepsilon, 101}$ and $M_{\varepsilon, 111}$ are calculated to be 290.9 and 379.5 GPa, respectively (Figures 4(a) and (b)). The thermal strain, $\varepsilon$, of fcc Co amounts to $\sim 6.1 \times 10^{-3}$. It produces $P_{\text {strain }}$ of $-3.3 \mathrm{MPa}$. The strain energy minimization favors $\{101\}$, whereas the surface energy minimization prefers $\{111\}$. The two driving force values are comparable to each other, and therefore, the two 
orientations could coexist, as revealed in the present observation (Figure 2(d)).

After cooling from $873 \mathrm{~K}\left(600{ }^{\circ} \mathrm{C}\right)$, the $(0001)$ texture component is observed to be dominant in the hcp phase, followed by the $\{2 \overline{110}\}$ component (Figure 2(b)). Considering the crystallographic orientation relationship between fcc $\mathrm{Co}$ and hcp Co, the (0001) component arises from the $\{111\}$ component, forming by the motion of SPDs along the slip planes parallel to the $\{111\}$ surface. The $\{2 \overline{11} 0\}$ component arises from the $\{101\}$ component. The (101) surface meets the $\{111\}$ planes at angles of 35.26 and $90 \mathrm{deg}$, and the $\{2 \overline{11} 0\}$ component forms by the motion of SPDs along $\{111\}$ planes meeting the (101) surface at an angle of $90 \mathrm{deg}$. Thus the slip planes of SPDs are parallel to the film surface for the (0001) texture component, and are normal to the film surface for the $\{2 \overline{110}\}$ component. Since the state of stress in a thin film due to film/substrate lattice-mismatch or thermal-mismatch approximates to plane stress, the resolved shear stress on slip planes parallel or normal to the film surface is zero, and it is unlikely that any of the dislocations lying on these planes migrate by such mismatch stresses. Therefore, the development of the (0001) and $\{2 \overline{11} 0\}$ texture components would be possible by stress inhomogeneity, due to stress gradient in the direction of the film thickness or due to the presence of extended defects, such as interphase boundaries and grain boundaries.

The (111) surface meets three equivalent types of $\{111\}$ planes at an angle of $70.53 \mathrm{deg}$, as sketched in Figure 5(a). If hcp zones different from (0001) emerge from the same fcc area, their (0001) planes are inclined from the surface by $70.53 \mathrm{deg}$. The corresponding component is therefore inclined from the (0001) component by $70.53 \mathrm{deg}$. The orientation is thus termed as (0001)/70.53 (Figure 5(a)). Likewise, in case hcp zones emerge from the $\{101\}$ component by the motion of SPDs along $\{111\}$ meeting the (101) surface at an angle of $35.26 \mathrm{deg}$ (Figure 5(b)), their (0001) planes are inclined from the surface by $35.26 \mathrm{deg}$ and the corresponding component is therefore inclined from the (0001) component by $35.26 \mathrm{deg}$ (hereafter, designated as (0001)/35.26).

The (0001)/70.53 and (0001)/35.26 texture components do not correspond to the minor orientations shown in Figures 1(d), (f), and (h). To attempt to explain the missing of the orientations, we calculate and compare the driving forces for martensitic growth by the surface energy minimization and the strain energy minimization. For strain energy consideration, we calculate the biaxial elastic modulus of hcp Co. (See, for details, Appendix.) The polar plot of the biaxial elastic modulus against the surface normal direction is shown in Figure 4(c). For hcp Co, the modulus of only the (0001) plane is independent of directions on the plane and thus the mean values are used in the plot. The mean modulus value depends on only the angle of inclination from (0001), as demonstrated in Figure 4(c). Therefore, simply, the biaxial elastic modulus can be plotted as a function of the angle of inclination from the (0001) plane (indicated by a white dotted arrow in Figure 4(c), as shown in Figure 4(d). The modulus value

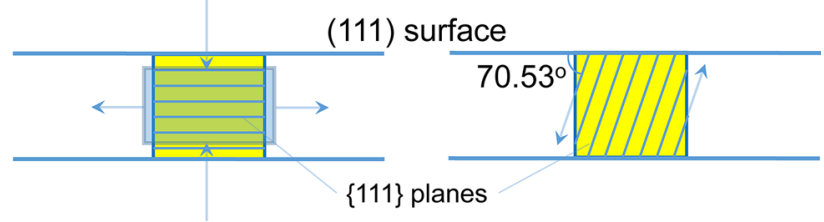

(a)

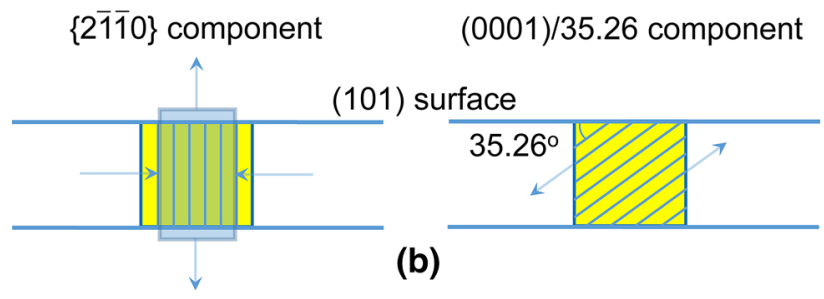

Fig. 5-Schematic diagram showing that (a) the (0001) and (0001)/ 70.53 components arise from the $\{111\}$ component and $(b)$ the $\{2 \overline{11} 0\}$ and $(0001) / 35.26$ components from the $\{101\}$ component. The yellow square indicates the grain of interest surrounded by neighboring grains and the lines inside represent the close-packed planes $(\{111\})$. The blue rectangle represents a macroscopic distortion with the lattice expanding parallel to and shrinking normal to the $\{111\}$ planes indicated by the arrows. The magnitudes of the distortion are exaggerated (Color figure online).

reaches the maximum of $380.2 \mathrm{GPa}$ at the (0001) plane. The minimum $(280.1 \mathrm{GPa})$ appears at the planes inclined by $\sim 57 \mathrm{deg}$, which correspond to pyramidal planes, such as $\{11 \overline{2} 2\}$, whose inclination angle is about 58.4 deg. Since, except for the (0001) plane, the modulus values of all other planes slightly vary with directions on the planes (Figure 4(d)), the aforementioned minimum is thus the mean value. The planes inclined from the (0001) plane by 90 deg correspond to prismatic planes, such as $\{2 \overline{11} 0\}$ and $\{10 \overline{1} 0\}$.

First, we consider the (0001) and (0001)/70.53 components arising from the $\{111\}$ component. The surface energy and biaxial elastic modulus values of the orientations considered are summarized in Table II. For the $(0001)$ and (0001)/70.53 components, the driving forces by the surface energy minimization $\left(P_{\text {surf }}\right)$ and by the strain energy minimization $\left(P_{\text {strain }}\right)$ are expressed as

$$
\begin{aligned}
& P_{\text {surf }}=2\left(\gamma_{0001}-\gamma_{(0001) / 70.53}\right) / d ; \\
& P_{\text {strain }}=\left(M_{\varepsilon, 0001}-M_{\varepsilon,(0001) / 70.53}\right) \cdot \varepsilon^{2} .
\end{aligned}
$$

Likewise, for the $\{2 \overline{11} 0\}$ and $(0001) / 35.26$ components,

$$
\begin{aligned}
& P_{\text {surf }}=2\left(\gamma_{2 \overline{110}}-\gamma_{(0001) / 35.26}\right) / d ; \\
& P_{\text {strain }}=\left(M_{\varepsilon, 2 \overline{11} 0}-M_{\varepsilon,(0001) / 35.26}\right) \cdot \varepsilon^{2},
\end{aligned}
$$

where $\varepsilon$ for hcp Co is the thermal strain of $4.1 \times 10^{-3}$ as calculated above.

As can be seen in Table II, the energetic consideration indicates that the (0001) component is preferred to the (0001)/70.53 component for the $\{111\}$ component, and the $(0001) / 35.26$ component is preferred to the $\{2 \overline{110}\}$ 
Table II. Summary of Values of Surface Energies and Biaxial Elastic Moduli Under the Equiaxial Strain-Plane Stress State for hep Orientations Transformed from fec $\{110\}$ and $\{111\}$

\begin{tabular}{|c|c|c|c|c|c|}
\hline fcc & hcp & $\gamma\left(\mathrm{J} / \mathrm{m}^{2}\right)^{*}$ & $M_{\varepsilon}(\mathrm{GPa})^{* *}$ & $P_{\text {surf }}(\mathrm{MPa})$ & $P_{\text {strain }}(\mathrm{MPa})$ \\
\hline \multirow[t]{2}{*}{111} & $(0001)$ & 2.993 & 380.2 & -40.3 & 1.6 \\
\hline & $(0001) / 70.53$ & $\sim 4$ & 286.6 & & \\
\hline \multirow[t]{2}{*}{101} & $\{2 \overline{110}\}$ & 4.841 & 297.7 & 25.6 & -0.08 \\
\hline & $(0001) / 35.26$ & $\sim 4.2$ & 302.4 & & \\
\hline
\end{tabular}

*Taken from Ref. [35].

**This study (Figures 4(c) and (d)).

component for the $\{101\}$ component. The magnitude of the driving force by the surface energy minimization is up to about two orders of magnitude larger than that by the strain energy minimization (Table II). The development of the (0001) texture from the $\{111\}$ component is attributed to the lowest surface energy of (0001) out of all hcp Co planes. ${ }^{[35]}$ However, for the $\{101\}$ component, the presence of the $\{2 \overline{11} 0\}$ texture and the missing of the (0001)/35.26 component are not elucidated by the energetic consideration based on minimization of the surface energy and the strain energy due to differential thermal expansion.

As noted in Section I, the martensitic transformation is associated with a macroscopic distortion. The lattice expands parallel to and shrinks normal to the closepacked plane. ${ }^{[13]}$ And the film in the present study is nanocrystalline. Therefore, the martensitic transformation occurring in a grain will produce strains because of a constraint imposed by adjacent grains. That is, we should consider not only the strain energy due to the thermal strain but also the strain energy produced by the constraint by neighboring grains. For a qualitative analysis of this strain energy, we account for the film geometry in the present study. That the mean grain size of the fcc phase is larger than the film thickness $(50 \mathrm{~nm})$ after prolonged annealing at $873 \mathrm{~K}\left(600^{\circ} \mathrm{C}\right)$ (Figure 3(a)) makes the film approximate to a bamboo structure in which grains completely traverse the film thickness and planes of grain boundaries and interphase boundaries are all nearly normal to the film surface. If the martensitic transformation occurs by the motion of SPDs along the slip planes which are normal to the film surface as for the $\{2 \overline{110} 0\}$ component, the compressive strain due to differential thermal expansion will be even reduced because the lattice shrinks parallel to the film surface, (Figure 5(b)), which thereby decrease the strain energy.

The (0001)/35.26 component is unfavorable in this aspect because it produces additional compressive strain, as sketched in Figure 5(b), which might explain its missing. However, the energetic consideration based on purely the surface energy and the thermal strain energy favors the (0001)/35.26 component. A plausible explanation is that the surface energy difference between $\{2 \overline{110}\}$ and the surface inclined from (0001) by $35.26 \mathrm{deg}$ (for the (0001)/35.26 component) specified in Table II might be a little exaggerated. If the surface energy difference was not so large as in Table II, the situation is expected to be reversed by a consideration of the strain energy provided by the geometrical constraint. Returning to the development of the (0001) component and the missing of the (0001)/70.53 components once more, both the two components produce additional compressive strain, increasing the total strain energy. However, in this case, the surface energy minimization is likely dominant because (0001) has the lowest surface energy. ${ }^{[35]}$ Taken together, our study seems to suggest that the development of texture components is controlled by not only the surface energy and the thermal strain energy but also the strain energy due to the geometrical constraint.

The increase in area fraction of the hcp phase with increasing annealing time (Figure 2(c)) leaves a clue as to a correlation between the mean grain size of the fcc phase and the martensitic transformation. The mean grain size of the fcc phase is expected to increase during annealing at $873 \mathrm{~K}\left(600{ }^{\circ} \mathrm{C}\right)$ with increasing annealing time. However, it is observed in the cooled structure to decrease with increasing annealing time, as shown in Figure 3(a). This is because the mean grain sizes plotted in Figure 3(a) is not obtained in situ during annealing. It is understood that, as annealing time increases, the mean grain size of the fcc phase, of course, increases during annealing at $873 \mathrm{~K}\left(600^{\circ} \mathrm{C}\right)$, which seemingly leads to the increase in area fraction of the hcp phase after cooling. Put it another way, the grain size increase in the fcc phase appears to enhance the martensitic transformation during cooling. The hcp grains formed by the enhanced transformation would swallow the fcc phase effectively during cooling, making the mean grain sizes appear to even decrease with increasing annealing time in the cooled structure, as demonstrated in Figure 3(a). The observation is also explained in terms of the geometrical constraint. As the number density of grain boundaries and interphase boundaries decreases due to grain growth at $873 \mathrm{~K}\left(600{ }^{\circ} \mathrm{C}\right)$, the SPDs responsible for the martensitic transformation could freely move without any interaction with the constraint, increasing the area fraction of the hcp phase (Figure 2(c)). The observation also suggests that martensites nucleate preferentially at the surfaces, including the $\mathrm{Co} / \mathrm{SiN}_{x}$ interface. If martensites were favored to nucleate at grain boundaries or interphase boundaries, the fraction of 
the hcp phase will be much higher than for a smaller grain-size regime, in contradiction to the observation.

\section{CONCLUDING REMARKS}

It is demonstrated that the texture evolution during annealing at $873 \mathrm{~K}\left(600{ }^{\circ} \mathrm{C}\right)$ and after the martensitic transformation in a nanocrystalline $\mathrm{Co}$ thin film is controlled by a combination of the surface energy minimization and the minimization of two types of strain energies (the strain energy due to differential thermal expansion and that produced by the geometrical constraint), such minimization that is closely associated with film stress and geometry. The martensitic transformation is observed to be incomplete, and thus all the film specimens examined show a mixture of the two phases. It is deduced from the crystallographic orientation relationship between fcc and hep Co that, during prolonged annealing at $873 \mathrm{~K}\left(600^{\circ} \mathrm{C}\right)$, the major texture in the fcc phase is $\{101\}$, followed by $\{111\}$. The $\{101\}$ texture is clarified by assuming that the Co film system is perfect elastic-plastic and also by relying on the concept of TF. The $\{111\}$ component is explained by the surface energy minimization. The texture development in the hcp phase after the martensitic transformation [(0001), followed by $\{2 \overline{110}\}]$ is understood by considering not only the surface energy and the strain energy due to differential thermal expansion, but also the strain energy due to the constraint imposed by neighboring grains. The increase in area fraction of the hcp phase with increasing annealing time at $873 \mathrm{~K}$ $\left(600{ }^{\circ} \mathrm{C}\right)$ is also understood by considering the strain energy due to the geometrical constraint. The observation strongly supports the possibility of surface nucleation of martensites. Presently, we do not have any appropriate model description embracing all of the terms, the surface energy, the strain energy due to differential thermal expansion, and the strain energy produced by the geometrical constraint. The development of such a model will provide crucial information for orientation and phase control in nanocrystalline $\mathrm{Co}$ and Co-based alloy thin films as magnetic recording media, stimulating further research, which are planned.

\section{ACKNOWLEDGMENTS}

The help of Mr. Dohyung Kim for the film deposition is appreciated. We thank Mr. Chang-Yeon Kim and Dr. Jin-Gyu Kim for their help at the ASTAR system. This research was supported by the Basic Science Research Program through the National Research Foundation of Korea (NRF) funded by the Ministry of Education (NRF-2013R1A1A2005181) (RIAM).

\section{APPENDIX: CALCULATIONS OF THE BIAXIAL ELASTIC MODULI UNDER EQUIBIAXIAL STRAIN, PLANE STRESS STATE OF FCC AND HCP CO}

The modulus $M_{\varepsilon}$ for a cubic symmetry material is expressed as ${ }^{[21,22]}$

$$
M_{\varepsilon}=\frac{1}{2} \cdot \frac{S_{11}^{\prime}+S_{22}^{\prime}-2 S_{12}^{\prime}}{S_{11}^{\prime} S_{22}^{\prime}-\left(S_{12}^{\prime}\right)^{2}}
$$

where the compliances $S_{11}{ }^{\prime}, S_{22}^{\prime}$, and $S_{12}{ }^{\prime}$ are expressed in terms of the compliances $S_{i j}$ referred to the symmetry axes, $x_{i}$, of the material as follows: ${ }^{[22]}$

$$
\begin{aligned}
S_{11}^{\prime}= & S_{11}+\left[S_{44}-2\left(S_{11}-S_{12}\right)\right]\left(a_{11}^{2} a_{12}^{2}+a_{12}^{2} a_{13}^{2}+a_{13}^{2} a_{11}^{2}\right), \\
S_{22}^{\prime}= & S_{11}+\left[S_{44}-2\left(S_{11}-S_{12}\right)\right]\left(a_{22}^{2} a_{21}^{2}+a_{21}^{2} a_{23}^{2}+a_{23}^{2} a_{22}^{2}\right), \\
S_{12}^{\prime}= & S_{12}-(1 / 2)\left[S_{44}-2\left(S_{11}-S_{12}\right)\right]\left(a_{11}^{2} a_{21}^{2}+a_{12}^{2} a_{22}^{2}\right. \\
& \left.+a_{13}^{2} a_{23}^{2}\right),
\end{aligned}
$$

where $a_{i j}$ 's are direction cosines relating $x_{i}^{\prime}$ to $x_{j}$, where $i$, $j=1,2,3$. The following compliances are used for fcc Co: $S_{11}=18.578, S_{44}=9.091$, and $S_{12}=-8.449$ in $\mathrm{TPa}^{-1}$ at $710 \mathrm{~K}\left(437^{\circ} \mathrm{C}\right) .^{[36]}$

The equation of the modulus for a hexagonal symmetry material is the same as for a cubic symmetry material. ${ }^{[21,22]}$ The compliances $S_{11}{ }^{\prime}, S_{22}{ }^{\prime}$, and $S_{12}{ }^{\prime}$ can be expressed in terms of the compliances $S_{i j}$ referred to the symmetry axes $x_{i}$ of the material as follows: ${ }^{[37]}$

$$
\begin{aligned}
S_{11}^{\prime}= & S_{11}\left(1-a_{13}^{2}\right)^{2}+S_{33} a_{13}^{4}+\left(S_{44}+2 S_{13}\right) a_{13}^{2}\left(1-a_{13}^{2}\right), \\
S_{22}^{\prime}= & S_{11}\left(1-a_{23}^{2}\right)^{2}+S_{33} a_{23}^{4}+\left(S_{44}+2 S_{13}\right) a_{23}^{2}\left(1-a_{23}^{2}\right), \\
S_{12}^{\prime}= & S_{11}\left(a_{11} a_{21}+a_{12} a_{22}\right)^{2}+S_{12}\left(a_{11} a_{22}-a_{12} a_{21}\right)^{2} \\
& +S_{13}\left(a_{13}^{2}+a_{23}^{2}-2 a_{13}^{2} a_{23}^{2}\right)+\left(S_{33}-S_{44}\right) a_{13}^{2} a_{23}^{2} .
\end{aligned}
$$

For hcp Co, $S_{11}=4.99, S_{33}=3.56, S_{44}=14.08$, $S_{12}=-2.36$, and $S_{13}=-0.87$ (in $\mathrm{TPa}^{-1}$ ) at room temperature. ${ }^{[38]}$

\section{REFERENCES}

1. P. Dova, H. Laidler, K. O'Grady, M.F. Toney, and M.F. Doerner: J. Appl. Phys., 1999, vol. 85, pp. 2775-81.

2. J. Li, M. Mirzamaani, X. Bian, M. Doerner, S. Duan, K. Tang, M. Toney, T. Arnoldussen, and M. Madison: J. Appl. Phys., 1999, vol. 85 , pp. $4286-91$.

3. S. Armyanov: Electrochim. Acta, 2000, vol. 45, pp. 3323-35.

4. Y. Takahashi, Y. Yajima, S. Kojima, and Y. Hosoe: J. Appl. Phys., 2000, vol. 87, pp. 5699-701.

5. Y. Takahashi, K. Tanahahshi, and Y. Hosoe: J. Appl. Phys., 2002, vol. 91, pp. 8022-24.

6. B. Lu and D.E. Laughlin: in The Physics of Ultra-High Density Magnetic Recording, Chap. 2, M.L. Plumer, J. van Ek, and D. Weller, eds., Springer, Berlin, 2001. 
7. S.N. Piramanayagam: J. Appl. Phys., 2007, vol. 102, pp. 011301-1011301-22.

8. E.A. Owen and D.M. Jones: Proc. Phys. Soc. Lond. B, 1954, vol. 67 , pp. $456-66$.

9. J.O. Nelson and C.J. Altstetter: Trans. Metall. Soc. AIME, 1964, vol. 230, pp. 1577-83.

10. A. Munier, J.E. Bidaux, R. Schaller, and C. Esnouf: J. Mater. Res., 1990, vol. 5, pp. 769-75.

11. R. Bauer, E.A. Jägle, W. Baumann, and E.J. Mittemeijer: Philos. Mag., 2011, vol. 91, pp. 437-57.

12. H.T. Hesemann, P. Müllner, O. Kraft, and E. Arzt: J. Phys. IV, 2003, vol. 112 , pp. 107-10.

13. T. Waitz and H.P. Karnthaler: Acta Mater., 1997, vol. 45, pp. 837-47.

14. W. Sucksmith and J.E. Thompson: Proc. R. Soc. Lond. A, 1954 , vol. 225, pp. 362-75.

15. D.M. Paige, B. Szpunar, and B.K. Tanner: J. Magn. Magn. Mater., 1984, vol. 44, pp. 239-48.

16. D.N. Lee: Z. Metallkde., 2005, vol. 96, pp. 259-68.

17. P. Moeck, S. Rouvimov, E.F. Rauch, M. Véron, H. Kirmse, I. Häusler, W. Neumann, D. Bultreys, Y. Maniette, and S. Nicolopoulos: Cryst. Res. Technol., 2011, vol. 46, pp. 589-606.

18. J.H. Cho, A.D. Rollett, and K.H. Oh: Metall. Mater. Trans. A, 2004, vol. 35A, pp. 1075-86.

19. V. Yamakov, D. Wolf, S.R. Phillpot, and H. Gleiter: Acta Mater., 2002, vol. 50, pp. 61-73.

20. B.E. Sundquist: Acta Metall., 1964, vol. 12, pp. 67-86.

21. J.M. Zhang and K.W. Xu: Appl. Surf. Sci., 2002, vol. 185, pp. $177-82$

22. D.N. Lee: Thin Solid Films, 2003, vol. 434, pp. 183-89; ibid 2012, vol. 520, p. 3708 (corrigendum).

23. http://www.kayelaby.npl.co.uk/general_physics/2_3/2_3_5.html. Accessed 4 Sept 2014.
24. L.B. Freund and S. Suresh: Thin Film Materials: Stress, Defect Formation and Surface Evolution, Cambridge University Press, Cambridge, 2003, p. 94.

25. G.I. Taylor: J. Inst. Met., 1938, vol. 62, pp. 307-24.

26. G.Y. Chin and W.L. Mammel: Trans. Metall. Soc. AIME, 1967, vol. 239 , pp. $1400-05$.

27. J.F.W. Bishop and R. Hill: Philos. Mag., 1951, vol. 42, pp. 414-21.

28. D.N. Lee, H.N. Han, and S.J. Kim: Proc. 15th Int. Conf. Textures of Materials (ICOTOM 15) (Symposium 10: Rolling and Annealing Textures of Silver Sheets), TMS, Pittsburgh, 2008.

29. S.J. Kim, H.N. Han, H.T. Jeong, and D.N. Lee: Mater. Res. Innov., 2011, vol. 15 (Suppl. 1), pp. S390-S394.

30. K.H. Oh, S.M. Park, Y.M. Koo, and D.N. Lee: Mater. Sci. Eng. A, 2011, vol. 528, pp. 6455-62.

31. C.C. Merriman, D.P. Field, and P. Trivedi: Mater. Sci. Eng. A, 2008, vol. 494, pp. $28-35$.

32. S.B. Lee, D.-I. Kim, S.-H. Hong, and D.N. Lee: Metall. Mater. Trans. A, 2013, vol. 44A, pp. 152-62.

33. M. Aldén, H.L. Skriver, S. Mirbt, and B. Johansson: Surf. Sci., 1994, vol. 315, pp. 157-72.

34. O. Fruchart, A. Masseboeuf, J.C. Toussaint, and P. Bayle-Guillemaud: J. Phys. Cond. Matter, 2013, vol. 25, pp. 496002-1-496002-8.

35. J.M. Zhang, D.D. Wang, and K.W. Xu: Appl. Surf. Sci., 2006, vol. 253, pp. 2018-24.

36. B. Strauss, F. Frey, W. Petry, J. Trampenau, K. Nicolaus, S.M. Shapiro, and J. Bossy: Phys. Rev. B, 1996, vol. 54, pp. 6035-38.

37. D.N. Lee: Texture and Related Phenomena, 2nd ed., The Korean Institute of Metals and Materials, Seoul, 2014, p. 101.

38. R.F. Hearmon: in Landolt-Börnstein Tables, Group III, vol. 11, K.H. Hellwege and A.M. Hellwege, eds., Springer, Berlin, 1979, pp. $1-154$. 